\title{
Iterative approximation methods for mixed equilibrium problems for a countable family of quasi- $\phi$-asymptotically nonexpansive multivalued mappings in Banach spaces
}

Rabian Wangkeeree* and Pakkapon Preechasilp

*Correspondence:

rabianw@nu.ac.th Department of Mathematics, Faculty of Science, Naresuan University, Phitsanulok, 65000, Thailand

\begin{abstract}
In this paper, we prove the existence of a solution of the mixed equilibrium problem $\operatorname{MEP}(f, \varphi, C)$ by using the KKM mapping in a Banach space setting. Then, by virtue of this result, we introduce a hybrid iterative scheme for finding a common element of the set of solutions of $\operatorname{MEP}(f, \varphi, C)$ and the set of common fixed points of a countable family of quasi- $\phi$-asymptotically nonexpansive multivalued mappings. Furthermore, we prove that the sequences generated by the hybrid iterative scheme converge strongly to a common element of the set of solutions of $\operatorname{MEP}(f, \varphi, C)$ and the set of common fixed points of a countable family of quasi- $\phi$-asymptotically nonexpansive multivalued mappings.
\end{abstract}

Keywords: mixed equilibrium problems; shrinking projection method; KKM mappings; multivalued mappings

\section{Introduction}

Let $E$ be a Banach space with the norm $\|\cdot\|$ and the dual $E^{*}$. We denote by $\mathbb{N}$ and $\mathbb{R}$ the sets of positive integers and real numbers, respectively. Also, we denote the normalized duality mapping from $E$ to $2^{E^{*}}$ by $J$ defined by

$$
J x=\left\{x^{*} \in E^{*}:\left\langle x, x^{*}\right\rangle=\|x\|^{2}=\left\|x^{*}\right\|^{2}\right\}, \quad \forall x \in E,
$$

where $\langle\cdot, \cdot\rangle$ denotes the generalized duality pairing. Let $C$ be a nonempty, closed and convex subset of a Banach space $E$. The bifunction $f: C \times C \rightarrow \mathbb{R}$ is said to be relaxed $\xi$-monotone if there exists a function $\xi: E \rightarrow \mathbb{R}$ positively homogeneous of degree $p$, that is, $\xi(t z)=t^{p} \xi(z)$ for all $t>0$ and $z \in E$, where $p>1$ is a constant such that

$$
f(x, y)+f(y, x) \leq \xi(y-x) \quad \text { for all } x, y \in C .
$$

If $\xi=0$, then $f$ is monotone, i.e.,

$$
f(x, y)+f(y, x) \leq 0 \quad \text { for all } x, y \in C .
$$

○2013 Wangkeeree and Preechasilp; licensee Springer. This is an Open Access article distributed under the terms of the Creative Commons Attribution License (http://creativecommons.org/licenses/by/2.0), which permits unrestricted use, distribution, and reproduction in any medium, provided the original work is properly cited. 
Example 1.1 Let $E=\mathbb{R}$ and $C=[0,1]$. A bifunction $f: C \times C \rightarrow \mathbb{R}$ is defined by

$$
f(x, y)=y(y-x), \quad \forall x, y \in[0,1]
$$

It is easy to see that $f(x, y)+f(y, x)=(x-y)^{2} \geq 0$. If we put $\xi(x)=x^{2}$ for all $x \in \mathbb{R}$, then $f$ is relaxed $\xi$-monotone, but not monotone.

Let us consider the bifunction $f: C \times C \rightarrow \mathbb{R}$ and a function $\varphi: C \rightarrow \mathbb{R}$. The mixed equilibrium problem (in short, $\operatorname{MEP}(f, \varphi, C)$ ) is to find $\tilde{x} \in C$ such that

$$
f(\tilde{x}, y)+\varphi(y)-\varphi(\tilde{x}) \geq 0, \quad \forall y \in C .
$$

Problem (1.2) was studied by Ceng and Yao [1], Cholamjiak and Suantai [2] in Hilbert spaces and Banach spaces, resp. By using the well-known KKM technique, they gave the existence and uniqueness of solutions of the $\operatorname{MEP}(f, \varphi, C)$ when $f$ is monotone.

In the case of $f(x, y)=\langle A x, \eta(y, x)\rangle$, where $A: C \rightarrow E^{*}$ and $\eta: C \times C \rightarrow E$, problem (1.2) is reduced to the following variational-like inequality problem (in short, $\operatorname{VLIP}(A, \varphi, C)$ ), which is to find $\tilde{x} \in C$ such that

$$
\langle A(\tilde{x}), \eta(y, \tilde{x})\rangle+\varphi(y)-\varphi(\tilde{x}) \geq 0, \quad \forall y \in C .
$$

Problem (1.3) was studied by Fang and Huang [3]. By using the KKM technique and $\eta-\xi$ monotonicity of the mapping $A$, they obtained the existence of solutions of the variationallike inequality problem (1.3) in a real reflexive Banach space.

In particular, if $\varphi \equiv 0$, problem (1.2) is reduced to the well-known equilibrium problem (in short, $E P(f, C)$ ), which is to find $\tilde{x} \in C$ such that

$$
f(\tilde{x}, y) \geq 0, \quad \forall y \in C
$$

The $E P(f, C)$ includes fixed point problems, optimization problems, variational inequality problems and Nash equilibrium problems as special cases (see also [4-6]).

Let $S$ be a mapping from $C$ into itself. A mapping $S$ is said to be Lipschitz if there exists a constant $L>0$ such that $\|S x-S y\| \leq L\|x-y\|$ for all $x, y \in C$. $S$ is said to be nonexpansive, when $L=1$. A point $p \in C$ is said to be a fixed point of $S$ if $S p=p$. A point $p \in C$ is said to be an asymptotic fixed point of $S$ if there exists a sequence $\left\{x_{n}\right\} \subset C$ such that $x_{n} \rightarrow x \in E$ and $\lim _{n \rightarrow \infty}\left\|x_{n}-S x_{n}\right\|=0$. Denote the set of all fixed points of $S$ and the set of all asymptotic fixed points of $S$ by $F(S)$ and $\hat{F}(S)$, respectively.

Now, we assume that $E$ is a smooth, strictly convex and reflexive Banach space. The Lyapunov function $\phi: E \times E \rightarrow \mathbb{R}^{+}$is defined by

$$
\phi(x, y)=\|x\|^{2}-2\langle x, J y\rangle+\|y\|^{2}, \quad \forall x, y \in E .
$$

A mapping $S: C \rightarrow C$ is said to be relatively nonexpansive (see also [7-9]) if the following conditions are satisfied:

(1) $F(S)$ is nonempty;

(2) $\phi(p, S x) \leq \phi(p, x)$ for all $x \in C, p \in F(S)$;

(3) $\hat{F}(S)=F(S)$. 
Lemma 1.2 [8] Let C be a nonempty, closed and convex subset of a smooth, strictly convex and reflexive Banach space $E$, and let $T$ be a relatively nonexpansive mapping from $C$ into itself. Then $F(T)$ is closed and convex.

In 2008, Takahashi and Zembayashi [10] introduced the following iterative scheme which is called the shrinking projection method:

$$
\left\{\begin{array}{l}
x_{0} \in C, \quad C_{0}=C, \\
y_{n}=J^{-1}\left[\alpha_{n} J x_{0}+\left(1-\alpha_{n}\right) J S x_{n}\right], \\
u_{n} \in C \quad \text { such that } \\
f\left(u_{n}, y\right)+\frac{1}{r_{n}}\left\langle y-u_{n}, J u_{n}-J w_{n}\right\rangle \geq 0, \quad \forall y \in C, \\
C_{n+1}=\left\{v \in C_{n}: \phi\left(v, u_{n}\right) \leq \phi\left(v, x_{n}\right)\right\}, \\
x_{n+1}=\Pi_{C_{n+1}} x_{0}, \quad n \geq 0,
\end{array}\right.
$$

where $J$ is the duality mapping on $E, \Pi_{C}$ is the generalized projection from $E$ onto $C$ and $S$ is relatively nonexpansive single-valued mapping. They proved that the sequence $\left\{x_{n}\right\}$ converges strongly to a common element of the set of fixed points of a relatively nonexpansive single-valued mapping and the set of solutions of an equilibrium problem under appropriate conditions in a uniformly smooth and uniformly convex Banach space.

In the case of single-valued mapping, many authors such as in references [8, 9, 11-19] studied the problem of finding a common element of the set of fixed points of a nonexpansive or relatively nonexpansive mapping and the set of solutions of an equilibrium problem in the framework of Hilbert spaces and Banach spaces.

Let $N(C)$ and $C B(C)$ denote the family of nonempty subsets and nonempty closed bounded subsets of $C$, respectively. The Hausdorff metric on $C B(C)$ is defined by

$$
H(A, B)=\max \left\{\sup _{a \in A} d(a, B), \sup _{b \in B} d(A, b)\right\}
$$

for all $A, B \in C B(C)$, where $d(x, D)=\inf \{\|x-y\|, y \in D\}$. Homaeipour and Razani [20] have defined the relatively nonexpansive multivalued mapping as follows.

A multivalued mapping $S: C \rightarrow N(C)$ is said to be relatively nonexpansive if the following conditions are satisfied:

(1) $F(S)$ is nonempty;

(2) $\phi(p, z) \leq \phi(p, x)$ for all $x \in C, p \in F(S), z \in S x$;

(3) $\hat{F}(S)=F(S)$.

It is obvious that the class of relatively nonexpansive multivalued mappings contains properly the class of relatively nonexpansive multivalued mappings (for example, see [20]). They introduced the following iterative sequence for finding a fixed point of the relatively nonexpansive multivalued mapping $S: C \rightarrow N(C)$ :

$$
\left\{\begin{array}{l}
x_{1} \in C \\
x_{n+1}=\Pi_{C}\left(\alpha_{n} J\left(x_{n}\right)+\left(1-\alpha_{n}\right) J\left(z_{n}\right)\right), \quad z_{n} \in S x_{n}, \forall n \geq 1
\end{array}\right.
$$

where $\left\{\alpha_{n}\right\} \subset[0,1]$. Moreover, they proved weak and strong convergence theorems for a single relatively nonexpansive multivalued mapping in a uniformly convex and uniformly smooth Banach space $E$. 
A multivalued mapping $S: C \rightarrow C B(C)$ is said to be quasi- $\phi$-nonexpansive [21, 22] if $F(S) \neq \emptyset$ and

$$
\phi(p, z) \leq \phi(p, x), \quad \forall x \in C, p \in F(S), z \in S x .
$$

$S: C \rightarrow C B(C)$ is said to be quasi- $\phi$-asymptotically nonexpansive $[21,22]$ if $F(S) \neq \emptyset$ and there exists a real sequence $l_{n} \subset[1,+\infty)$ with $l_{n} \rightarrow 1$ such that

$$
\phi\left(p, z_{n}\right) \leq l_{n} \phi(p, x), \quad \forall x \in C, p \in F(S), z_{n} \in S^{n} x .
$$

We remark from the above definitions that the class of quasi- $\phi$-asymptotically nonexpansive multivalued mappings contains properly the class of quasi- $\phi$-nonexpansive multivalued mappings as a subclass, and the class of quasi- $\phi$-nonexpansive multivalued mappings contains properly the class of relatively nonexpansive mappings as a subclass.

Recently, Yi [21] introduced the following modifying Halpern iterative sequence for a quasi- $\phi$-asymptotically nonexpansive multivalued mapping $S$. Let $\left\{x_{n}\right\}$ be the sequence generated by

$$
\left\{\begin{array}{l}
x_{0} \in C, \quad C_{0}=C \\
y_{n}=J^{-1}\left[\alpha_{n} J x_{0}+\left(1-\alpha_{n}\right) J z_{n}\right], \quad z_{n} \in S^{n} x_{n}, \\
C_{n+1}=\left\{v \in C_{n}: \phi\left(v, y_{n}\right) \leq \alpha_{n} \phi\left(v, x_{0}\right)+\left(1-\alpha_{n}\right) \phi\left(v, x_{n}\right)+\zeta_{n}\right\} \\
x_{n+1}=\Pi_{C_{n+1}} x_{0}, \quad n \geq 0,
\end{array}\right.
$$

where $\zeta_{n}=\left(l_{n}-1\right) \sup _{p \in F(S)} \phi\left(p, x_{n}\right)$ and $\left\{\alpha_{n}\right\} \subset(0,1)$. Under suitable conditions, the author proved that $\left\{x_{n}\right\}$ converges strongly to $\Pi_{F(S)} x_{0}$.

Motivated and inspired by the above results, we investigate the problem of finding a common element of the set of solutions of $\operatorname{MEP}(f, \varphi, C)$ and the set of common fixed points of a countable family of quasi- $\phi$-asymptotically nonexpansive multivalued mappings in Banach spaces.

The rest of the paper is organized as follows. In Section 2, we provide necessary concepts and lemmas. In Section 3, we derive the existence and uniqueness of solutions of the auxiliary problems for the $\operatorname{MEP}(f, \varphi, C)$ when the bifunction $f$ is relaxed $\xi$-monotone by using the well-known KKM technique. In Section 4, we prove that our proposed hybrid iterative scheme converges strongly to a common element of the set of $\operatorname{MEP}(f, \varphi, C)$ and the set of common fixed points of a countable family of quasi- $\phi$-asymptotically nonexpansive multivalued mappings. In Section 5, we give an application for a system of mixed equilibrium problems. The last section is the conclusions.

\section{Preliminaries}

Throughout this paper, let $E$ be a real Banach space and $E^{*}$ be its dual space. We write $x_{n} \rightarrow$ $x$ (respectively $x_{n}-^{*} x$ ) to indicate that the sequence $\left\{x_{n}\right\}$ weakly (respectively weak*) converges to $x$; as usual $x_{n} \rightarrow x$ will symbolize strong convergence. Let $S(E)=\{x \in E$ : $\|x\|=1\}$ denote the unit sphere of a Banach space $E$.

A Banach space $E$ is said to have a Gâteaux differentiable norm (we also say that $E$ is smooth) if the limit

$$
\lim _{t \rightarrow 0} \frac{\|x+t y\|-\|x\|}{t}
$$


exists for each $x, y \in S(E)$. A Banach space $E$ is said to have a uniformly Gâteaux differentiable norm if for each $y$ in $S(E)$, the limit (2.1) is uniformly attained for $x \in S(E)$; a Fréchet differentiable norm if for each $x \in S(E)$, the limit (2.1) is attained uniformly for $y \in S(E)$; a uniformly Fréchet differentiable norm (we also say that $E$ is uniformly smooth) if the limit (2.1) is attained uniformly for $(x, y) \in S(E) \times S(E)$.

A Banach space $E$ is said to strictly convex if $\frac{\|x+y\|}{2}<1$ for $x, y \in S(E), x \neq y$; uniformly convex if, for any $\varepsilon \in(0,2]$, there exists $\delta>0$ such that for any $x, y \in S(E),\|x-y\| \geq \varepsilon$ implies $\left\|\frac{x+y}{2}\right\| \leq 1-\delta$.

Remark 2.1 The following basic properties for the Banach space $E$ and for the normalized duality mapping $J$ can be found in Cioranescu [23].

(i) $E$ ( $E^{*}$, resp.) is uniformly convex if and only if $E$ ( $E^{*}$, resp.) is uniformly smooth.

(ii) If $E$ is smooth, then $J$ is single-valued and norm-to-weak continuous.

(iii) If $E$ is reflexive, then $J$ is onto.

(iv) If $E$ is strictly convex, then $J x \cap J y \neq \emptyset$ for all $x, y \in E$.

(v) Each uniformly convex Banach space $E$ has the Kadec-Klee property, that is, for any sequence $\left\{x_{n}\right\} \subset E$, if $x_{n} \rightarrow x \in E$ and $\left\|x_{n}\right\| \rightarrow\|x\|$, then $x_{n} \rightarrow x \in E$.

(vi) If $E$ is a strictly convex reflexive Banach space, then $J^{-1}$ is hemicontinuous, that is, $J^{-1}$ is norm-to-weak*-continuous.

Recall the Lyapunov function $\phi$ defined by

$$
\phi(x, y)=\|x\|^{2}-2\langle x, J y\rangle+\|y\|^{2}, \quad \forall x, y \in E .
$$

It follows from the definition of the function $\phi$ that

$$
\phi\left(x, J^{-1}(\lambda J y+(1-\lambda) J z)\right) \leq \lambda \phi(x, y)+(1-\lambda) \phi(x, z), \quad \forall \lambda \in[0,1] \text { and } x, y, z \in E .
$$

Following Alber [24], the generalized projection $\Pi_{C}$ from $E$ onto $C$ is defined by

$$
\Pi_{C} x=\arg \min _{y \in C} \phi(y, x), \quad \forall x \in C
$$

If $E$ is a Hilbert space, then $\phi(y, x)=\|y-x\|^{2}$ and $\Pi_{C}$ is the metric projection of $H$ onto $C$. We known the following lemma for generalized projection.

Lemma 2.2 [24] Let E be a smooth, strictly convex and reflexive Banach space, and let $C$ be a nonempty, closed and convex subset of $E$. Then the following conclusions hold:

(i) $\phi(x, y)=0$ if and only if $x=y$ for all $x, y \in E$;

(ii) $\phi\left(x, \Pi_{C} y\right)+\phi\left(\Pi_{C} y, y\right) \leq \phi(x, y)$ for all $x \in C$, for all $y \in E$;

(iii) if $x \in E$ and $z \in C$, then $z=\Pi_{C} x \Leftrightarrow\langle z-y$,Jx-Jz $\geq 0$ for all $y \in C$.

Now, let us recall the following useful concepts and results.

Definition 2.3 Let $B$ be a subset of a topological vector space $X$. A mapping $G: B \rightarrow 2^{X}$ is called a KKM mapping if $\operatorname{co}\left\{x_{1}, x_{2}, \ldots, x_{m}\right\} \subset \bigcup_{i=1}^{m} G\left(x_{i}\right)$ for $x_{i} \in B$ and $i=1,2, \ldots, m$, where co $A$ denotes the convex hull of the set $A$. 
Lemma 2.4 [25] Let B be a nonempty subset of a Hausdorff topological vector space $X$, and let $G: B \rightarrow 2^{X}$ be a KKM mapping. If $G(x)$ is closed for all $x \in B$ and is compact for at least one $x \in B$, then $\bigcap_{x \in B} G(x) \neq \emptyset$.

Definition 2.5 A multivalued mapping $S: C \rightarrow C B(C)$ is said to be closed if for any sequence $\left\{x_{n}\right\} \subset C$ with $x_{n} \rightarrow x \in C$ and $d\left(y, S\left(x_{n}\right)\right) \rightarrow 0, d(y, S(x))=0$.

The following lemmas can be found in [21].

Lemma 2.6 [21, Lemma 2.8] Let E be a real uniformly smooth and strictly convex Banach space with the Kadec-Klee property, and let $C$ be a nonempty, closed and convex subset of $E$. Let $\left\{x_{n}\right\}$ and $\left\{y_{n}\right\}$ be two sequences in $C$ such that $x_{n} \rightarrow p$ and $\phi\left(x_{n}, y_{n}\right) \rightarrow 0$, then $y_{n} \rightarrow p$.

Lemma 2.7 [21, Lemma 2.9] Let E be a real uniformly smooth and strictly convex Banach space with the Kadec-Klee property, and let $C$ be a nonempty, closed and convex subset of $E$. Let $S: C \rightarrow C B(C)$ be a closed and quasi- $\phi$-asymptotically nonexpansive multivalued mapping with nonnegative real sequences $\left\{l_{n}\right\} \subset[1, \infty)$, if $l_{n} \rightarrow 1$, then the fixed point set $F(S)$ of $S$ is a closed and convex subset of $C$.

\section{Existence results of mixed equilibrium problem}

In this chapter, we prove the existence theorem for $\operatorname{MEP}(f, \varphi, C)$ by using the KKM technique.

Before solving mixed equilibrium problem (1.2), let us assume the following conditions for a bifunction $f: C \times C \rightarrow \mathbb{R}$ :

(A1) $f(x, x)=0$ for all $x \in C$;

(A2) $f$ is relaxed $\xi$-monotone, i.e.,

$$
f(x, y)+f(y, x) \leq \xi(y-x)
$$

(A3) for all $y \in C, f(\cdot, y)$ is upper hemicontinuous, i.e., for all $x, y, z \in C$,

$$
\limsup _{t \downarrow 0} f(t z+(1-t) x, y) \leq f(x, y)
$$

(A4) for all $x \in C, f(x, \cdot)$ is convex and lower-semicontinuous.

Lemma 3.1 Let C be a nonempty, closed and convex subset of a real smooth, strictly convex and reflexive Banach space $E$, let $f$ be a bifunction from $C \times C$ to $\mathbb{R}$ satisfying (A1)-(A4), and let $\varphi$ be a lower semicontinuous and convex function from $C$ to $\mathbb{R}$. Let $z \in C$. Then the following problems (3.1) and (3.2) are equivalent:

Find $\tilde{x} \in C$ such that $f(\tilde{x}, y)+\varphi(y)+\frac{1}{2}\|y\|^{2}-\frac{1}{2}\|\tilde{x}\|^{2}-\langle y-\tilde{x}, J z\rangle \geq \varphi(\tilde{x})$,

$$
\forall y \in C
$$

Find $\tilde{x} \in C$ such that $\varphi(y)+\frac{1}{2}\|y\|^{2}-\frac{1}{2}\|\tilde{x}\|^{2}-\langle y-\tilde{x}, J z\rangle+\xi(y-x) \geq f(y, \tilde{x})+\varphi(\tilde{x})$,

$$
\forall y \in C .
$$


Proof Let $\tilde{x} \in C$ be a solution of problem (3.1). It follows from (A2) that

$$
\begin{aligned}
0 & \leq f(\tilde{x}, y)+\varphi(y)-\varphi(\tilde{x})+\frac{1}{2}\|y\|^{2}-\frac{1}{2}\|\tilde{x}\|^{2}-\langle y-\tilde{x}, J z\rangle \\
& =f(\tilde{x}, y)+f(y, \tilde{x})-f(y, \tilde{x})+\varphi(y)-\varphi(\tilde{x})+\frac{1}{2}\|y\|^{2}-\frac{1}{2}\|\tilde{x}\|^{2}-\langle y-\tilde{x}, J z\rangle \\
& \leq \xi(y-\tilde{x})-f(y, \tilde{x})+\varphi(y)-\varphi(\tilde{x})+\frac{1}{2}\|y\|^{2}-\frac{1}{2}\|\tilde{x}\|^{2}-\langle y-\tilde{x}, J z\rangle, \quad \forall y \in C .
\end{aligned}
$$

Thus $\tilde{x} \in C$ is a solution of problem (3.2).

Conversely, let $\tilde{x} \in C$ be a solution of problem (3.2). For any $t \in(0,1]$, we put

$$
y_{t}=(1-t) \tilde{x}+t y .
$$

Then $y_{t} \in C$, because of the convexity of $C$. Since $\tilde{x} \in C$ is a solution of problem (3.2), it follows that

$$
\begin{aligned}
f\left(y_{t}, \tilde{x}\right) & \leq \varphi\left(y_{t}\right)-\varphi(\tilde{x})+\frac{1}{2}\left\|y_{t}\right\|^{2}-\frac{1}{2}\|\tilde{x}\|^{2}-\left\langle y_{t}-\tilde{x}, J z\right\rangle+\xi\left(y_{t}-x\right) \\
& =\varphi\left(y_{t}\right)-\varphi(\tilde{x})+\frac{1}{2}\left\|y_{t}\right\|^{2}-\frac{1}{2}\|\tilde{x}\|^{2}-\left\langle y_{t}-\tilde{x}, J z\right\rangle+t^{p} \xi(y-x) .
\end{aligned}
$$

Using (A1) and (A4), we have

$$
0=f\left(y_{t}, y_{t}\right) \leq(1-t) f\left(y_{t}, \tilde{x}\right)+t f\left(y_{t}, y\right)
$$

and so

$$
t\left(f\left(y_{t}, \tilde{x}\right)-f\left(y_{t}, y\right)\right) \leq f\left(y_{t}, \tilde{x}\right)
$$

The convexity of the function $\varphi$ implies that

$$
\varphi\left(y_{t}\right)=\varphi((1-t) \tilde{x}+t y) \leq(1-t) \varphi(\tilde{x})+t \varphi(y) .
$$

It follows from (3.5)-(3.7) and the convexity of $\frac{1}{2}\|\cdot\|^{2}$ that

$$
\begin{array}{rl}
0 & f\left(y_{t}, y_{t}\right) \\
\leq & (1-t) f\left(y_{t}, \tilde{x}\right)+t f\left(y_{t}, y\right) \\
\leq & (1-t)\left[\varphi\left(y_{t}\right)-\varphi(\tilde{x})+\frac{1}{2}\left\|y_{t}\right\|^{2}-\frac{1}{2}\|\tilde{x}\|^{2}-\left\langle y_{t}-\tilde{x}, J z\right\rangle+t^{p} \xi(y-\tilde{x})\right]+t f\left(y_{t}, y\right) \\
\leq & t f\left(y_{t}, y\right)+(1-t)\left[(1-t) \varphi(\tilde{x})+t \varphi(y)-\varphi(\tilde{x})+\frac{(1-t)}{2}\|\tilde{x}\|^{2}+\frac{t}{2}\|y\|^{2}\right. \\
& \left.\quad-\frac{1}{2}\|\tilde{x}\|^{2}-t\langle y-\tilde{x}, J z\rangle+t^{p} \xi(y-\tilde{x})\right] \\
\leq & t f\left(y_{t}, y\right)+(1-t) t\left[\varphi(y)-\varphi(\tilde{x})+\frac{1}{2}\|y\|^{2}-\frac{1}{2}\|\tilde{x}\|^{2}-\langle y-\tilde{x}, J z\rangle+t^{p-1} \xi(y-\tilde{x})\right] .
\end{array}
$$


This implies that

$$
0 \leq f\left(y_{t}, y\right)+(1-t)\left[\varphi(y)-\varphi(\tilde{x})+\frac{1}{2}\|y\|^{2}-\frac{1}{2}\|\tilde{x}\|^{2}-\langle y-\tilde{x}, J z\rangle+t^{p-1} \xi(y-\tilde{x})\right] .
$$

Taking the upper limit $t \rightarrow 0$ in (3.9), by (A3) and $p>1$, we get that

$$
\varphi(\tilde{x}) \leq f(\tilde{x}, y)+\varphi(y)+\frac{1}{2}\|y\|^{2}-\frac{1}{2}\|\tilde{x}\|^{2}-\langle y-\tilde{x}, J z\rangle, \quad \forall y \in C .
$$

Therefore, $\tilde{x}$ is also a solution of problem (3.1). This completes the proof.

Lemma 3.2 Let $C$ be a nonempty, bounded, closed and convex subset of a real smooth, strictly convex and reflexive Banach space $E$, let $f$ be a bifunction from $C \times C$ to $\mathbb{R}$ satisfying (A1) and (A4), and let $\varphi$ be a lower semicontinuous and convex function from $C$ to $\mathbb{R}$. Let $z \in C$. Assume that

(i) $\xi: E \rightarrow \mathbb{R}$ is weakly upper semicontinuous; that is, for any net $\left\{x_{\beta}\right\}, x_{\beta}$ converges to $x$ in $\sigma\left(E, E^{*}\right)$, which implies that $\xi(x) \leq \liminf \xi\left(x_{\beta}\right)$.

Then the solution set of problem (3.1) is nonempty; that is, there exists $\tilde{x} \in C$ such that

$$
f(\tilde{x}, y)+\varphi(y)+\frac{1}{2}\|y\|^{2}-\frac{1}{2}\|\tilde{x}\|^{2}-\langle y-\tilde{x}, J z\rangle \geq \varphi(\tilde{x}), \quad \forall y \in C .
$$

Proof Let $z \in C$. Define two set-valued mappings $F_{z}, G_{z}: C \rightarrow 2^{C}$ as follows:

$$
F_{z}(y)=\left\{x \in C: f(x, y)+\varphi(y)+\frac{1}{2}\|y\|^{2}-\frac{1}{2}\|x\|^{2}-\langle y-x, J z\rangle \geq \varphi(x)\right\}
$$

and

$$
G_{z}(y)=\left\{x \in C: \varphi(y)+\frac{1}{2}\|y\|^{2}-\frac{1}{2}\|x\|^{2}-\langle y-x, J z\rangle+\xi(y-x) \geq f(y, x)+\varphi(x)\right\}
$$

for every $y \in C$. It is easily seen that $y \in F_{z}(y)$ and $y \in G_{z}(y)$, and hence $F_{z}(y)$ and $G_{z}(y)$ are nonempty.

(a) We claim that $F_{z}$ is a KKM mapping. If $F_{z}$ is not a KKM mapping, then there exist $\left\{y_{1}, \ldots, y_{n}\right\} \subset K$ and $\mu_{i}>0, i=1, \ldots, n$, such that

$$
\sum_{i=1}^{n} \mu_{i}=1, \quad y_{0}=\sum_{i=1}^{n} \mu_{i} y_{i} \notin \bigcup_{i=1}^{n} F_{z}\left(y_{i}\right) .
$$

By the definition of $F_{z}$, we have

$$
f\left(y_{0}, y_{i}\right)+\varphi\left(y_{i}\right)-\varphi\left(y_{0}\right)+\frac{1}{2}\left\|y_{i}\right\|^{2}-\frac{1}{2}\left\|y_{0}\right\|^{2}-\left\langle y_{i}-y_{0}, J z\right\rangle<0
$$

for all $i=1, \ldots, n$. It follows from (A1), (A4), the convexity of $\varphi$ and $\frac{1}{2}\|\cdot\|^{2}$ that

$$
\begin{aligned}
0 & =f\left(y_{0}, y_{0}\right)+\varphi\left(y_{0}\right)-\varphi\left(y_{0}\right)+\frac{1}{2}\left\|y_{0}\right\|^{2}-\frac{1}{2}\left\|y_{0}\right\|^{2}-\left\langle y_{0}-y_{0}, J z\right\rangle \\
& \leq \sum_{i=1}^{n} \mu_{i}\left(f\left(y_{0}, y_{i}\right)+\varphi\left(y_{i}\right)-\varphi\left(y_{0}\right)+\frac{1}{2}\left\|y_{i}\right\|^{2}-\frac{1}{2}\left\|y_{0}\right\|^{2}-\left\langle y_{i}-y_{0}, J z\right\rangle\right)<0,
\end{aligned}
$$

which is a contradiction. This implies that $F_{z}$ is a KKM mapping. 
(b) We claim that $G_{z}$ is a KKM mapping. It is sufficient to show that

$$
F_{z}(y) \subset G_{z}(y), \quad \forall y \in C .
$$

For any given $y \in C$, taking $x \in F_{z}(y)$, then

$$
f(x, y)+\varphi(y)-\varphi(x)+\frac{1}{2}\|y\|^{2}-\frac{1}{2}\|x\|^{2}-\langle y-x, J z\rangle \geq 0 .
$$

It follows from the relaxed $\xi$-monotonicity of $f$ that

$$
\varphi(y)+\frac{1}{2}\|y\|^{2}-\frac{1}{2}\|x\|^{2}-\langle y-x, J z\rangle+\xi(y-x) \geq f(y, x)+\varphi(x) .
$$

It follows that $x \in G_{z}(y)$ and so

$$
F_{z}(y) \subset G_{z}(y), \quad \forall y \in C .
$$

This implies that $G_{z}$ is also a KKM mapping.

(c) We show that $G_{z}(y)$ is weakly closed for all $y \in C$. Let $\left\{u_{n}\right\}$ be a sequence in $G_{z}(y)$ such that $u_{n} \rightarrow u$ as $n \rightarrow \infty$. It then follows from $u_{n} \in G_{z}(y)$ that

$$
\varphi(y)+\frac{1}{2}\|y\|^{2}-\frac{1}{2}\left\|u_{n}\right\|^{2}-\left\langle y-u_{n}, J z\right\rangle+\xi\left(y-u_{n}\right) \geq f\left(y, u_{n}\right)+\varphi\left(u_{n}\right), \quad \forall y \in C .
$$

By (A4), the weak lower semicontinuity of $\varphi$ and $\|\cdot\|^{2}$, and the weak upper semicontinuity of $\xi$, we obtain from (3.15) that

$$
\begin{aligned}
f(y, u)+\varphi(u) \leq & \liminf _{n \rightarrow \infty} f\left(y, u_{n}\right)+\liminf _{n \rightarrow \infty} \varphi\left(u_{n}\right) \\
\leq & \liminf _{n \rightarrow \infty}\left\{f\left(y, u_{n}\right)+\varphi\left(u_{n}\right)\right\} \\
\leq & \limsup _{n \rightarrow \infty}\left\{\varphi(y)+\frac{1}{2}\|y\|^{2}-\frac{1}{2}\left\|u_{n}\right\|^{2}-\left\langle y-u_{n}, J z\right\rangle+\xi\left(y-u_{n}\right)\right\} \\
\leq & \varphi(y)+\frac{1}{2}\|y\|^{2}-\liminf _{n \rightarrow \infty} \frac{1}{2}\left\|u_{n}\right\|^{2}-\liminf _{n \rightarrow \infty}\left\langle y-u_{n}, J z\right\rangle \\
& +\limsup _{n \rightarrow \infty} \xi\left(y-u_{n}\right) \\
= & \varphi(y)+\frac{1}{2}\|y\|^{2}-\frac{1}{2}\|u\|^{2}-\langle y-u, J z\rangle+\xi(y-u) .
\end{aligned}
$$

This shows that $u \in G_{z}(y)$ and hence $G_{z}(y)$ is weakly closed for all $y \in C$.

(d) We prove that $G_{z}(y)$ is weakly compact. Since $C$ is a closed, bounded and convex subset of a reflexive Banach space $E$, it is weakly compact. Again, since $G_{z}(y)$ is a weakly closed subset of $C$, we also have $G_{z}(y)$ is weakly compact.

By using (a)-(d) and Lemma 2.4 and Lemma 3.1 that

$$
\bigcap_{y \in C} F_{z}(y)=\bigcap_{y \in C} G_{z}(y) \neq \emptyset
$$

Hence, there exists $x_{0} \in C$ satisfying inequality (3.10). This completes the proof. 
Proposition 3.3 Let $C$ be a nonempty, closed and convex subset of a real smooth, strictly convex and reflexive Banach space $E, \psi: C \rightarrow \mathbb{R}$ be a convex function. The following two inequalities are equivalent:

$$
\text { there exists } \tilde{x} \in C \text { such that } \psi(\tilde{x})=0 \text { and } \psi(y)+\langle y-\tilde{x}, J \tilde{x}\rangle \geq 0, \quad \forall y \in C
$$

and

$$
\text { there exists } \tilde{x} \in C \text { such that } \psi(\tilde{x})=0 \text { and } \psi(y)+\frac{1}{2}\|y\|^{2}-\frac{1}{2}\|\tilde{x}\|^{2} \geq 0, \quad \forall y \in C .
$$

Proof Let $\tilde{x}$ satisfy (3.16). It is well known that

$$
\langle y-x, J x\rangle \leq \frac{1}{2}\|y\|^{2}-\frac{1}{2}\|x\|^{2}, \quad \forall x, y \in E .
$$

Then

$$
\begin{aligned}
0 & \leq \psi(y)+\langle y-\tilde{x}, J \tilde{x}\rangle \\
& =\psi(y)+\langle y-\tilde{x}, J \tilde{x}\rangle \\
& \leq \psi(y)+\frac{1}{2}\|y\|^{2}-\frac{1}{2}\|\tilde{x}\|^{2} .
\end{aligned}
$$

Let $\tilde{x}$ satisfy (3.17). For any $t \in(0,1]$, let $y_{t}=(1-t) \tilde{x}+t y$. Then $y_{t} \in C$ because of the convexity of $C$, and so

$$
\psi\left(y_{t}\right)+\frac{1}{2}\left\|y_{t}\right\|^{2}-\frac{1}{2}\|\tilde{x}\|^{2}-\left\langle y_{t}-\tilde{x}, J z\right\rangle \geq 0
$$

Notice that in a real smooth, strictly convex reflexive Banach space $E$, the duality mapping $J$ is single-valued, $1-1$, and onto. Since $\frac{1}{2}\|\cdot\|^{2}$ is continuous and Gâteaux differentiable, from the mean value theorem, there exists $\alpha_{t} \in(0,1)$ such that

$$
\frac{1}{2}\left\|y_{t}\right\|^{2}-\frac{1}{2}\|\tilde{x}\|^{2}=\left\langle y_{t}-\tilde{x}, J w_{\alpha_{t}}\right\rangle
$$

where $w_{\alpha_{t}}=\alpha_{t} \tilde{x}+\left(1-\alpha_{t}\right) y_{t}$. Hence

$$
\begin{aligned}
0 & \leq \psi(y)+\frac{1}{2}\|y\|^{2}-\frac{1}{2}\|\tilde{x}\|^{2} \\
& =\psi\left(y_{t}\right)+\left\langle y_{t}-\tilde{x}, J w_{\alpha_{t}}\right\rangle \\
& \leq(1-t) \psi(\tilde{x})+t \psi(y)+t\left\langle y-\tilde{x}, J w_{\alpha_{t}}\right\rangle \\
& =t \psi(y)+t\left\langle y-\tilde{x}, J w_{\alpha_{t}}\right\rangle .
\end{aligned}
$$

Dividing $t$ in the above inequality, we get

$$
0 \leq \psi(y)+\left\langle y-\tilde{x}, J w_{\alpha_{t}}\right\rangle .
$$


By the existence of $w_{\alpha_{t}}, w_{\alpha_{t}} \rightarrow \tilde{x}$ as $t \rightarrow 0$. Since $J$ is norm-to-weak* continuous, we have that

$$
0 \leq \psi(y)+\langle y-\tilde{x}, J \tilde{x}\rangle
$$

This completes the proof.

Remark 3.4 If $\tilde{x} \in C$ is a solution of (3.1), then

$$
f(\tilde{x}, y)+\varphi(y)+\frac{1}{2}\|y\|^{2}-\frac{1}{2}\|\tilde{x}\|^{2}-\langle y-\tilde{x}, J z\rangle \geq \varphi(\tilde{x}), \quad \forall y \in C .
$$

For any fixed $z \in E$, we put $\psi_{\tilde{x}}(y)=f(\tilde{x}, y)+\varphi(y)-\varphi(\tilde{x})-\langle y-\tilde{x}, J z\rangle$ for all $y \in C$. Obviously, $\psi_{\tilde{x}}(\tilde{x})=0$ and $\psi_{\tilde{x}}$ is a convex function, since the linearity of a duality mapping and the convexity of $f(\tilde{x}, \cdot)$ and $\varphi$. Hence

$$
\psi_{\tilde{x}}(y)+\frac{1}{2}\|y\|^{2}-\frac{1}{2}\|\tilde{x}\|^{2} \geq 0, \quad \forall y \in C .
$$

It then follows from Proposition 3.3 that $\tilde{x}$ is a solution of the following problem:

$$
f(\tilde{x}, y)+\varphi(y)+\langle y-\tilde{x}, J \tilde{x}-J z\rangle \geq \varphi(\tilde{x}), \quad \forall y \in C .
$$

The existence result relaxes the results of Ceng and Yao [1] and Cholamjiak and Suantai [2], because of the $\xi$-monotonicity of $f$.

Lemma 3.5 Let $C$ be a closed, bounded and convex subset of a uniformly smooth, strictly convex Banach space $E$, let $f$ be a bifunction from $C \times C$ to $\mathbb{R}$ satisfying (A1)-(A4), and let $\varphi$ be a lower semicontinuous and convex function from $C$ to $\mathbb{R}$. Suppose further that

(i) $\xi: E \rightarrow \mathbb{R}$ is weakly upper semicontinuous;

(ii) $\xi(y-x)+\xi(x-y) \leq 0$

Define a mapping $T_{r}(z): E \rightarrow C$ as follows:

$$
T_{r}(z)=\left\{x \in C: f(x, y)+\varphi(y)+\frac{1}{r}\langle y-x, J x-J z\rangle \geq \varphi(x), \forall y \in C\right\} .
$$

Then

(1) $T_{r}$ is single-valued;

(2) $T_{r}$ is a firmly nonexpansive mapping, i.e., for all $x, y \in E$,

$$
\left\langle T_{r}(x)-T_{r}(y), J T_{r}(x)-J T_{r}(y)\right\rangle \leq\left\langle T_{r}(x)-T_{r}(y), J x-J y\right\rangle
$$

(3) $F\left(T_{r}\right)=M E P(f, \varphi, C)$;

(4) $\operatorname{MEP}(f, \varphi, C)$ is closed and convex;

(5) $\phi\left(p, T_{r} x\right)+\phi\left(T_{r} x, x\right) \leq \phi(p, x)$.

Proof If $f(x, y): C \times C \rightarrow \mathbb{R}$ satisfies (A1)-(A4) and $\varphi: C \rightarrow \mathbb{R}$ is convex lower semicontinuous, then for any $r>0$, we known that $r f(x, y)$ and $r \varphi$ are also. We have from Lemma 3.2 and Remark 3.4 that $T_{r} z$ is nonempty for all $z \in E$. 
(1) For each $z \in E$, let $x_{1}, x_{2} \in T_{r}(z)$. Then

$$
f\left(x_{1}, x_{2}\right)+\varphi\left(x_{2}\right)+\frac{1}{r}\left\langle x_{2}-x_{1}, J x_{1}-J z\right\rangle \geq \varphi\left(x_{1}\right)
$$

and

$$
f\left(x_{2}, x_{1}\right)+\varphi\left(x_{1}\right)+\frac{1}{r}\left\langle x_{1}-x_{2}, J x_{2}-J z\right\rangle \geq \varphi\left(x_{2}\right) .
$$

Adding (3.19) and (3.20), we have

$$
f\left(x_{2}, x_{1}\right)+f\left(x_{1}, x_{2}\right)+\frac{1}{r}\left\langle x_{1}-x_{2}, J x_{2}-J z\right\rangle+\frac{1}{r}\left\langle x_{2}-x_{1}, J x_{1}-J z\right\rangle \geq 0,
$$

and so

$$
f\left(x_{2}, x_{1}\right)+f\left(x_{1}, x_{2}\right)+\frac{1}{r}\left\langle x_{2}-x_{1}, J x_{1}-J x_{2}\right\rangle \geq 0 .
$$

By the relaxed $\xi$-monotonicity of $f$, we know that

$$
\left\langle x_{2}-x_{1}, J x_{1}-J x_{2}\right\rangle \geq-r \xi(y-x) .
$$

In (3.21) exchanging the position of $x_{1}$ and $x_{2}$, we get

$$
f\left(x_{1}, x_{2}\right)+f\left(x_{2}, x_{1}\right)+\frac{1}{r}\left\langle x_{1}-x_{2}, J x_{2}-J x_{1}\right\rangle \geq 0,
$$

and so

$$
\left\langle x_{1}-x_{2}, J x_{2}-J x_{1}\right\rangle \geq-r \xi(y-x) .
$$

Now, adding inequalities (3.22) and (3.24), by using (ii), we have

$$
\left\langle x_{2}-x_{1}, J x_{1}-J x_{2}\right\rangle \geq-\frac{r}{2}(\xi(y-x)+\xi(y-x)) \geq 0 .
$$

Since $J$ is monotone and $E$ is strictly convex, we have $x_{1}=x_{2}$, and so $T_{r}(z)$ is single-valued.

(2) For $x, y \in C$, we have that

$$
f\left(T_{r} x, T_{r} y\right)+\varphi\left(T_{r} y\right)-\varphi\left(T_{r} x\right)+\frac{1}{r}\left\langle T_{r} y-T_{r} x, J T_{r} x-J x\right\rangle \geq 0
$$

and

$$
f\left(T_{r} y, T_{r} x\right)+\varphi\left(T_{r} x\right)-\varphi\left(T_{r} y\right)+\frac{1}{r}\left\langle T_{r} x-T_{r} y, J T_{r} y-J y\right\rangle \geq 0 .
$$

Adding the two inequalities above, we get that

$$
f\left(T_{r} x, T_{r} y\right)+f\left(T_{r} y, T_{r} x\right)+\frac{1}{r}\left\langle T_{r} y-T_{r} x, J T_{r} x-J T_{r} y-J x+J y\right\rangle \geq 0 .
$$


From (A2), we obtain that

$$
\xi\left(T_{r} y-T_{r} x\right)+\frac{1}{r}\left\langle T_{r} y-T_{r} x, J T_{r} x-J T_{r} y-J x+J y\right\rangle \geq 0 .
$$

In (3.25), interchanging the position of $T_{r} x$ and $T_{r} y$, we get

$$
\xi\left(T_{r} x-T_{r} y\right)+\frac{1}{r}\left\langle T_{r} x-T_{r} y, J T_{r} y-J T_{r} x-J y+J x\right\rangle \geq 0 .
$$

Again adding (3.24) and (3.25), we get

$$
\xi\left(T_{r} y-T_{r} x\right)+\xi\left(T_{r} x-T_{r} y\right)+\frac{2}{r}\left\langle T_{r} y-T_{r} x, J T_{r} x-J T_{r} y-J x+J y\right\rangle \geq 0 .
$$

It follows from (ii) and $r>0$ that

$$
\left\langle T_{r} x-T_{r} y, J T_{r} x-J T_{r} y\right\rangle \leq\left\langle T_{r} y-T_{r} x, J x-J y\right\rangle .
$$

(3) Indeed, we have the following:

$$
\begin{aligned}
p \in F\left(T_{r}\right) & \Leftrightarrow \quad p=T_{r} p \\
& \Leftrightarrow f(p, y)+\varphi(y)-\varphi(p)+\frac{1}{r}\langle y-p, J p-J p\rangle \geq 0, \quad \forall y \in C \\
& \Leftrightarrow f(p, y)+\varphi(y)-\varphi(p) \geq 0, \quad \forall y \in C \\
& \Leftrightarrow \quad p \in \operatorname{MEP}(f, \varphi, C) .
\end{aligned}
$$

(4) We claim that $\operatorname{MEP}(f, \varphi, C)$ is closed and convex. Indeed, from (3) we have $\operatorname{MEP}(f, \varphi, C)=F\left(T_{r}\right)$. From (2) we have, for all $x, y \in C$,

$$
\left\langle T_{r}(x)-T_{r}(y), J T_{r}(x)-J T_{r}(y)\right\rangle \leq\left\langle T_{r}(x)-T_{r}(y), J x-J y\right\rangle .
$$

Moreover, we have

$$
\begin{aligned}
\phi\left(T_{r} x, T_{r} y\right)+\phi\left(T_{r} y, T_{r} x\right) & =2\left\|T_{r} x\right\|^{2}-\left\langle T_{r} x, J T_{r} y\right\rangle-\left\langle T_{r} y, J T_{r} x\right\rangle+2\left\|T_{r} y\right\|^{2} \\
& =2\left\langle T_{r} x, J T_{r} x-J T_{r} y\right\rangle+2\left\langle T_{r} y, T_{r} y-J T_{r} x\right\rangle \\
& =2\left\langle T_{r} x-T_{r} y, J T_{r} x-J T_{r} y\right\rangle
\end{aligned}
$$

and

$$
\begin{aligned}
\phi( & \left.T_{r} x, y\right)+\phi\left(T_{r} y, x\right)-\phi\left(T_{r} x, x\right)-\phi\left(T_{r} y, y\right) \\
& =\left\|T_{r} x\right\|^{2}-2\left\langle T_{r} x, J y\right\rangle+\|y\|^{2}+\left\|T_{r} y\right\|^{2}-\left\langle T_{r} y, J x\right\rangle+\|x\|^{2} \\
& =-\left\|T_{r} x\right\|^{2}+2\left\langle T_{r} x, J x\right\rangle-\|x\|^{2}-\left\|T_{r} y\right\|^{2}+\left\langle T_{r} y, J y\right\rangle-\|y\|^{2} \\
& =2\left\langle T_{r} x, J x-J y\right\rangle-2\left\langle T_{r} y, J x-J y\right\rangle \\
& =2\left\langle T_{r} x-T_{r} y, J x-J y\right\rangle .
\end{aligned}
$$


Hence, we have

$$
\phi\left(T_{r} x, T_{r} y\right)+\phi\left(T_{r} y, T_{r} x\right) \leq \phi\left(T_{r} x, y\right)+\phi\left(T_{r} y, x\right)-\phi\left(T_{r} x, x\right)-\phi\left(T_{r} y, y\right) .
$$

So, we have, for any $x, y \in C$,

$$
\phi\left(T_{r} x, T_{r} y\right)+\phi\left(T_{r} y, T_{r} x\right) \leq \phi\left(T_{r} x, y\right)+\phi\left(T_{r} y, x\right) .
$$

Next, we show that $\hat{F}\left(T_{r}\right)=\operatorname{MEP}(f, \varphi, C)$. Let $p \in \hat{F}\left(T_{r}\right)$. Then there exists $\left\{u_{n}\right\} \subset E$ such that $z_{n} \rightarrow p$ and $\lim _{n \rightarrow \infty}\left(u_{n}-T_{r} u_{n}\right)=0$. Moreover, we get that $T_{r} u_{n} \rightarrow p$. Since the duality mapping $J$ is uniformly continuous on a bounded set, we get

$$
\lim _{n \rightarrow \infty} \frac{1}{r}\left\|J u_{n}-J T_{r} u_{n}\right\|=0
$$

From the definition of $T_{r}$, we have

$$
f\left(T_{r} u_{n}, y\right)+\frac{1}{r}\left\langle y-T_{r} u_{n}, J T_{r} u_{n}-J u_{n}\right\rangle \geq \varphi\left(T_{r} u_{n}\right)
$$

Since

$$
\begin{aligned}
& \frac{1}{r}\left\langle y-T_{r} u_{n}, J T_{r} u_{n}-J u_{n}\right\rangle \\
& \quad \geq \varphi\left(T_{r} u_{n}\right)-\varphi(y)-f\left(T_{r} u_{n}, y\right) \\
& \quad \geq \varphi\left(T_{r} u_{n}\right)-\varphi(y)+f\left(y, T_{r} u_{n}\right)-\xi\left(y-T_{r} u_{n}\right) .
\end{aligned}
$$

By (A4), the convexity and lower semicontinuity of $\varphi(x)$ and the weak upper semicontinuity of $\xi$, we can obtain that

$$
\begin{aligned}
0 & \geq \liminf _{n \rightarrow \infty}\left\{\varphi\left(T_{r} u_{n}\right)-\varphi(y)+f\left(y, T_{r} u_{n}\right)-\xi\left(y-T_{r} u_{n}\right)\right\} \\
& =\liminf _{n \rightarrow \infty} \varphi\left(T_{r} u_{n}\right)-\varphi(y)+\liminf _{n \rightarrow \infty} f\left(y, T_{r} u_{n}\right)-\limsup _{n \rightarrow \infty} \xi\left(y-T_{r} u_{n}\right) \\
& \geq \varphi(p)-\varphi(y)+f(y, p)-\xi(y-p) .
\end{aligned}
$$

This implies that

$$
\varphi(p)-\varphi(y)+f(y, p)-\xi(y-p) \leq 0, \quad \forall y \in C .
$$

Let $y \in K$ and set $p_{t}=t y+(1-t) p$ for $t \in(0,1]$. It follows from (A1) and (A4) that

$$
\begin{aligned}
0 & =f\left(p_{t}, p_{t}\right) \\
& \leq(1-t) f\left(p_{t}, p\right)+t f\left(p_{t}, y\right) .
\end{aligned}
$$

The convexity of the function $\varphi$ implies that

$$
\varphi\left(p_{t}\right)=\varphi((1-t) p+t y) \leq(1-t) \varphi(p)+t \varphi(y) .
$$


It follows from (3.28)-(3.30) that

$$
\begin{aligned}
0 & =f\left(p_{t}, p_{t}\right) \\
& \leq(1-t) f\left(p_{t}, p\right)+t f\left(p_{t}, y\right) \\
& \leq t f\left(p_{t}, y\right)+(1-t)\left[\varphi\left(p_{t}\right)-\varphi(p)+t^{p} \xi(y-p)\right] \\
& \leq t f\left(p_{t}, y\right)+(1-t)\left[(1-t) \varphi(p)+t \varphi(y)-\varphi(p)+t^{p} \xi(y-p)\right] \\
& =t f\left(p_{t}, y\right)+(1-t) t\left[\varphi(y)-\varphi(p)+t^{p-1} \xi(y-p)\right] .
\end{aligned}
$$

Dividing by $t$, we have

$$
0 \leq f\left(p_{t}, y\right)+(1-t)\left[\varphi(y)-\varphi(p)+t^{p-1} \xi(y-p)\right] .
$$

By (A3) and $p>1$, taking the upper limit $t \rightarrow 0$ in (3.33), we get

$$
f(p, y)+\varphi(y) \geq \varphi(p), \quad \forall y \in C
$$

Hence, $p \in \operatorname{MEP}(f, \varphi, C)$, and so $F\left(T_{r}\right)=\operatorname{MEP}(f, \varphi, C)=\hat{F}\left(T_{r}\right)$. Therefore, we have $T_{r}$ is a relatively nonexpansive mapping. From Lemma 1.2, $\operatorname{MEP}(f, \varphi, C)=F\left(T_{r}\right)$ is closed and convex.

(5) From (3.27) we have, for all $x, y \in E$,

$$
\phi\left(T_{r} x, T_{r} y\right)+\phi\left(T_{r} y, T_{r} x\right) \leq \phi\left(T_{r} x, y\right)+\phi\left(T_{r} y, x\right)-\phi\left(T_{r} x, x\right)-\phi\left(T_{r} y, y\right) .
$$

Letting $y=p \in F\left(T_{r}\right)$, we have

$$
\phi\left(p, T_{r} x\right)+\phi\left(T_{r} x, x\right) \leq \phi(p, x)
$$

This completes the proof.

\section{Strong convergence theorems}

Before proving the convergence theorem, we recall some definitions of a countable family of multivalued mappings $\left\{S_{i}: C \rightarrow C B(C)\right\}_{i=1}^{\infty}$.

Definition 4.1 $\left\{S_{i}\right\}_{i=1}^{\infty}$ is said to be a family of uniformly quasi- $\phi$-asymptotically nonexpansive mappings [15] if $\mathcal{F}:=\bigcap_{i=1}^{\infty} F\left(S_{i}\right) \neq \emptyset$ and there exists a sequence $\left\{l_{n}\right\} \subset[1, \infty)$ with $l_{n} \rightarrow 1$ such that for each $i \geq 1$,

$$
\phi\left(p, z_{n, i}\right) \leq l_{n} \phi(p, x), \quad \forall p \in \mathcal{F}, z_{n, i} \in S_{i}^{n} x, \forall n \geq 1 .
$$

Definition 4.2 A mapping $S: C \rightarrow C B(C)$ is said to be uniformly $L$-Lipschitz continuous [15] if there exists a constant $L>0$ such that $\left\|x_{n}-y_{n}\right\| \leq L\|x-y\|$ for all $x, y \in C, x_{n} \in T^{n} x$, $y_{n} \in T^{n} y$.

Theorem 4.3 Let E be a real uniformly smooth and strictly convex Banach space with the Kadec-Klee property, and let $C$ be a nonempty, bounded, closed and convex subset of E. Let 
$f$ be a bifunction from $C \times C$ to $\mathbb{R}$ satisfying (A1)-(A4), and let $\varphi$ be a lower semicontinuous and convex function from $C$ to $\mathbb{R}$. Let $\left\{S_{i}: C \rightarrow C B(C)\right\}_{i=1}^{\infty}$ be a family of closed and uniformly quasi- $\phi$-asymptotically nonexpansive multivalued mappings with a sequence $\left\{l_{n}\right\} \subset[1, \infty), l_{n} \rightarrow 1$. Suppose that for each $i \geq 1, S_{i}$ is uniformly $L_{i}$-Lipschitz continuous and $\mathcal{F} \cap \operatorname{MEP}(f, \varphi, C) \neq \emptyset$.

Let $\left\{x_{n}\right\}$ be a sequence in $C$ generated by

$$
\left\{\begin{array}{l}
x_{0} \in C, \quad C_{0}=C, \\
w_{n}=J^{-1}\left(\alpha_{n, 0} J x_{0}+\sum_{i=1}^{\infty} \alpha_{n, j} J z_{n, i}\right), \quad z_{n, i} \in S_{i}^{n} x_{n}, \\
u_{n} \in K \quad \text { such that } \\
f\left(u_{n}, y\right)+\varphi(y)+\frac{1}{r_{n}}\left\langle y-u_{n}, J u_{n}-J w_{n}\right\rangle \geq \varphi\left(u_{n}\right), \quad \forall y \in C, \\
C_{n+1}=\left\{v \in C_{n}: \phi\left(v, u_{n}\right) \leq \alpha_{n, 0} \phi\left(v, x_{0}\right)+\left(1-\alpha_{n, 0}\right) \phi\left(v, x_{n}\right)+\zeta_{n}\right\}, \\
x_{n+1}=\prod_{C_{n+1}} x_{0}, \quad n \geq 0,
\end{array}\right.
$$

where for each $\left\{r_{n}\right\}_{n=0}^{\infty} \subset[a, \infty)$ for some $a>0,\left\{\alpha_{n, i}\right\}_{n=0, i=0}^{\infty} \subset[0,1]$, and $\zeta_{n}=\sup _{u \in \mathcal{F}}\left(l_{n}-\right.$ 1) $\phi\left(u, x_{n}\right)$. If $\sum_{i=0}^{\infty} \alpha_{n, i}=1, \forall n \geq 0, \lim _{n \rightarrow \infty} \alpha_{n, 0}=0$, then $\left\{x_{n}\right\}$ converges strongly as $n \rightarrow \infty$ to $\Pi_{\Omega} x_{0}$, where $\Omega:=\mathcal{F} \cap \operatorname{MEP}(f, \varphi, C)$.

Proof We divide the proof into five steps. Firstly, we rewrite algorithm (4.1) as follows:

$$
\left\{\begin{array}{l}
x_{0} \in C, \quad C_{0}=C \\
w_{n}=J^{-1}\left(\alpha_{n, 0} J x_{0}+\sum_{i=1}^{\infty} \alpha_{n, i} J z_{n, i}\right), \quad z_{n, i} \in S_{i}^{n} x_{n}, \\
C_{n+1}=\left\{v \in C_{n}: \phi\left(v, T_{r_{n}} w_{n}\right) \leq \alpha_{n, 0} \phi\left(v, x_{0}\right)+\left(1-\alpha_{n, 0}\right) \phi\left(v, x_{n}\right)+\zeta_{n}\right\} \\
x_{n+1}=\Pi_{C_{n+1} x_{0}}, \quad n \geq 0,
\end{array}\right.
$$

where $T_{r}$ is the mapping defined by (3.18) for all $r>0$.

Step 1 . We first show that the sequence $\left\{x_{n}\right\}$ is well defined. It suffices to prove that $C_{n}$ is closed and convex and that $\Omega \subset C_{n}$ for all $n \geq 0$. Suppose that $C_{n}$ is closed and convex for some $n \geq 0$. By the definition of $\phi$, we have

$$
\begin{aligned}
C_{n+1}= & \left\{v \in C_{n}: \phi\left(v, u_{n}\right) \leq \alpha_{n, 0} \phi\left(v, x_{0}\right)+\left(1-\alpha_{n, 0}\right) \phi\left(v, x_{n}\right)+\zeta_{n}\right\} \\
= & \left\{v \in C: \phi\left(v, u_{n}\right) \leq \alpha_{n, 0} \phi\left(v, x_{0}\right)+\left(1-\alpha_{n, 0}\right) \phi\left(v, x_{n}\right)+\zeta_{n}\right\} \cap C_{n} \\
= & \left\{v \in C: 2 \alpha_{n, 0}\left\langle v, J x_{0}\right\rangle+2\left(1-\alpha_{n, 0}\right)\left\langle v, J x_{n}\right\rangle-2\left\langle v, J u_{n}\right\rangle\right. \\
& \left.\leq \alpha_{n, 0}\left\|x_{0}\right\|^{2}+\left(1-\alpha_{n, 0}\right)\left\|x_{n}\right\|^{2}-\left\|y_{n}\right\|^{2}+\zeta_{n}\right\} \cap C_{n} .
\end{aligned}
$$

This shows that $C_{n+1}$ is closed and convex. The conclusions are proved.

Step 2. Next, we prove that $\Omega \subset C_{n}$ for all $n \geq 0$. In fact, it is obvious that $\Omega \subset C_{0}:=C$. Suppose $\Omega \subset C_{n}$ for some $n \geq 0$. Hence, for any $p \in \Omega$, it follows from Lemma 3.5(5) that

$$
\begin{aligned}
\phi\left(p, u_{n}\right) & =\phi\left(p, T_{r_{n}} w_{n}\right) \leq \phi\left(p, w_{n}\right) \\
& =\phi\left(p, J^{-1}\left(\alpha_{n, 0} J x_{0}+\sum_{i=1}^{\infty} \alpha_{n, i} J z_{n, i}\right)\right) \\
& \leq \alpha_{n, 0} \phi\left(p, x_{0}\right)+\sum_{i=1}^{\infty} \alpha_{n, i} \phi\left(p, z_{n, i}\right)
\end{aligned}
$$




$$
\begin{aligned}
& \leq \alpha_{n, 0} \phi\left(p, x_{0}\right)+\left(1-\alpha_{n, 0}\right) l_{n} \phi\left(p, x_{n}\right) \\
& \leq \alpha_{n, 0} \phi\left(p, x_{0}\right)+\left(1-\alpha_{n, 0}\right)\left\{\phi\left(p, x_{n}\right)+\left(l_{n}-1\right) \phi\left(p, x_{n}\right)\right\} \\
& \leq \alpha_{n, 0} \phi\left(p, x_{0}\right)+\left(1-\alpha_{n, 0}\right)\left\{\phi\left(p, x_{n}\right)+\left(l_{n}-1\right) \sup _{p \in \mathcal{F}} \phi\left(p, x_{n}\right)\right\} \\
& =\alpha_{n, 0} \phi\left(p, x_{0}\right)+\left(1-\alpha_{n, 0}\right) \phi\left(p, x_{n}\right)+\zeta_{n} .
\end{aligned}
$$

This shows that $p \in \Omega \subset C_{n+1}$. Hence $\Omega \subset C_{n}$ for all $n \geq 0$.

Step 3. We show that $\left\{x_{n}\right\}$ converges strongly to some point $\tilde{x}$. Since $x_{n}=\Pi_{C_{n}} x_{0}$, from Lemma 2.2(iii), we have that

$$
\left\langle x_{n}-y, J x_{0}-J x_{n}\right\rangle \geq 0, \quad \forall y \in C_{n} .
$$

Also, since $\mathcal{F} \subset C_{n}$, we have

$$
\left\langle x_{n}-p, J x_{0}-J x_{n}\right\rangle \geq 0, \quad \forall p \in \mathcal{F}
$$

It follows from Lemma 2.2(ii) that for each $p \in \mathcal{F}$ and for each $n \geq 1$,

$$
\phi\left(x_{n}, x_{0}\right)=\phi\left(\Pi_{C_{n}} x_{0}, x_{0}\right) \leq \phi\left(p, x_{0}\right)-\phi\left(p, x_{n}\right) \leq \phi\left(p, x_{0}\right) .
$$

Therefore, $\left\{\phi\left(x_{n}, x_{0}\right)\right\}$ is bounded, and so is $\left\{x_{n}\right\}$. Since $x_{n}=\Pi_{C_{n}} x_{0}$ and $x_{n+1}=\Pi_{C_{n+1}} x_{0} \in$ $C_{n+1} \subset C_{n}$, we have

$$
\phi\left(x_{n}, p\right) \leq \phi\left(x_{n+1}, p\right), \quad \forall n \geq 0 .
$$

That is, $\left\{\phi\left(x_{n}, p\right)\right\}$ is a nondecreasing sequence, and so $\lim _{n \rightarrow \infty} \phi\left(x_{n}, p\right)$ exists. Since $E$ is reflexive, there exists a subsequence $\left\{x_{n_{i}}\right\} \subset\left\{x_{n}\right\}$ such that $x_{n_{i}} \rightarrow \tilde{x} \in C$. Since $C_{n}$ is closed, convex and $C_{n+1} \subset C_{n}$, we get that $C_{n}$ is weakly closed and $\tilde{x} \in C_{n}$ for all $n \geq 0$. Since $x_{n_{i}}=\Pi_{C_{n_{i}}} x_{0}$, we have

$$
\phi\left(x_{n_{i}}, x_{0}\right) \leq \phi\left(\tilde{x}, x_{0}\right), \quad \forall n_{i} \geq 0 .
$$

By the weak lower semicontinuity of $\|\cdot\|$, we have

$$
\begin{aligned}
\liminf _{n_{i} \rightarrow \infty} \phi\left(x_{n_{i}}, x_{0}\right) & =\liminf _{n_{i} \rightarrow \infty}\left(\left\|x_{n_{i}}\right\|^{2}-2\left\langle x_{n_{i}}, J x_{0}\right\rangle+\left\|x_{0}\right\|^{2}\right) \\
& \geq\|\tilde{x}\|^{2}-2\left\langle\tilde{x}, J x_{0}\right\rangle+\left\|x_{0}\right\|^{2} \\
& =\phi\left(\tilde{x}, x_{0}\right),
\end{aligned}
$$

and so

$$
\phi\left(\tilde{x}, x_{0}\right) \leq \liminf _{i \rightarrow \infty} \phi\left(x_{n_{i}}, x_{0}\right) \leq \limsup _{i \rightarrow \infty} \phi\left(x_{n_{i}}, x_{0}\right) \leq \phi\left(\tilde{x}, x_{0}\right)
$$

Therefore $\lim _{i \rightarrow \infty} \phi\left(x_{n_{i}}, x_{0}\right)=\left(\tilde{x}, x_{0}\right)$, and so $\left\|x_{n_{i}}\right\| \rightarrow\|\tilde{x}\|$. Since $E$ has the Kadec-Klee property and $x_{n_{i}} \rightarrow \tilde{x}$, we obtain that $x_{n_{i}} \rightarrow \tilde{x}$. Since the limit of $\left\{\phi\left(x_{n}, x_{0}\right)\right\}$ exists, this 
together with $\lim _{n \rightarrow \infty} \phi\left(x_{n_{i}}, x_{0}\right)=\phi\left(\tilde{x}, x_{0}\right)$ implies that $\lim _{n \rightarrow \infty} \phi\left(x_{n}, x_{0}\right)=\phi\left(\tilde{x}, x_{0}\right)$. If there exists a subsequence $\left\{x_{n_{j}}\right\} \subset\left\{x_{n}\right\}$ such that $x_{n_{j}} \rightarrow \hat{x}$. Then by Lemma 2.2(ii) we have that

$$
\begin{aligned}
\phi(\tilde{x}, \hat{x}) & =\lim _{i, j \rightarrow \infty} \phi\left(x_{n_{i}}, x_{n_{j}}\right)=\lim _{i, j \rightarrow \infty} \phi\left(x_{n_{i}}, \Pi_{\left.C_{n_{j}} x_{0}\right)}\right. \\
& \leq \lim _{i, j \rightarrow \infty}\left\{\phi\left(x_{n_{i}}, x_{0}\right)-\phi\left(\Pi_{C_{n_{j}}} x_{0}, x_{0}\right)\right\}=\lim _{i, j \rightarrow \infty}\left\{\phi\left(x_{n_{i}}, x_{0}\right)-\phi\left(x_{n_{j}}, x_{0}\right)\right\} \\
& =\phi\left(\tilde{x}, x_{0}\right)-\phi\left(\tilde{x}, x_{0}\right) .
\end{aligned}
$$

Hence $\tilde{x}=\hat{x}$, and so

$$
\lim _{n \rightarrow \infty} x_{n}=\tilde{x}
$$

This implies that

$$
\zeta_{n}=\left(l_{n}-1\right) \sup _{p \in \mathcal{F}} \phi\left(p, x_{n}\right) \rightarrow 0 .
$$

Step 4. We prove that $\tilde{x} \in \mathcal{F}$. Since $x_{n}=\Pi_{C_{n}} x_{0}$, by Lemma 2.2(ii) we get that

$$
\phi\left(x, x_{n}\right) \leq \phi\left(x, x_{0}\right)-\phi\left(x_{n}, x_{0}\right), \quad \forall x \in C_{n} .
$$

Since $x_{n+1} \in C_{n+1} \subset C_{n}$, we get that

$$
\phi\left(x_{n+1}, x_{n}\right) \leq \phi\left(x_{n+1}, x_{0}\right)-\phi\left(x_{n}, x_{0}\right) .
$$

Since $\lim _{n \rightarrow \infty} \phi\left(x_{n}, x_{0}\right)=\phi\left(\tilde{x}, x_{0}\right)$, we get that

$$
\lim _{n \rightarrow \infty} \phi\left(x_{n+1}, x_{n}\right)=0
$$

Since $x_{n+1} \in C_{n+1}$, we have from (4.1) that

$$
\phi\left(x_{n+1}, u_{n}\right) \leq \alpha_{n, 0} \phi\left(v, x_{0}\right)+\left(1-\alpha_{n, 0}\right) \phi\left(x_{n+1}, x_{n}\right)+\zeta_{n} .
$$

By $\lim _{n \rightarrow \infty} \alpha_{n, 0}=0,(4.5)$ and (4.6), it implies that

$$
\lim _{n \rightarrow \infty} \phi\left(x_{n+1}, u_{n}\right)=0,
$$

which together with (4.4) and Lemma 2.6 give that

$$
\lim _{n \rightarrow \infty} u_{n}=\tilde{x} .
$$

Recall from (4.3) that

$$
\phi\left(p, u_{n}\right) \leq \phi\left(p, w_{n}\right) \leq \alpha_{n, 0} \phi\left(p, x_{0}\right)+\left(1-\alpha_{n, 0}\right) \phi\left(p, x_{n}\right)+\zeta_{n} .
$$

It follows from $\lim _{n \rightarrow \infty} \alpha_{n, 0}=0,(4.4),(4.5)$ and (4.9) that

$$
\lim _{n \rightarrow \infty} \phi\left(p, w_{n}\right)=\phi(p, \tilde{x}) .
$$


By Lemma 3.5, we get that

$$
\phi\left(u_{n}, w_{n}\right) \leq \phi\left(p, w_{n}\right)-\phi\left(p, u_{n}\right) \rightarrow 0 \quad \text { as } n \rightarrow \infty
$$

It follows from Lemma 2.6 and $\lim _{n \rightarrow \infty} u_{n}=\tilde{x}$ that

$$
\lim _{n \rightarrow \infty} w_{n}=\tilde{x}
$$

From (4.1), we get that

$$
\left\|J w_{n}-J z_{n, i}\right\|=\alpha_{n, 0}\left\|J x_{0}-J z_{n, i}\right\|, \quad \forall i \geq 1
$$

Since $\lim _{n \rightarrow \infty} \alpha_{n, 0}=0$ and the boundedness of $\left\{z_{n, i}\right\}$,

$$
\lim _{n \rightarrow \infty}\left\|J w_{n}-J z_{n, i}\right\|=0, \quad \forall i \geq 1
$$

Since $J w_{n} \rightarrow J \tilde{x}$, we have from the uniform continuity of $J$ that $J z_{n_{i}} \rightarrow J \tilde{x}$ for all $i \geq 1$. Remark 2.1(vi) gives that

$$
z_{n, i} \rightarrow \tilde{x}, \quad \forall i \geq 1
$$

Again, since

$$
\left|\left\|z_{n, i}\right\|-\|\tilde{x}\|\right|=\left|\left\|J z_{n, i}\right\|-\|J \tilde{x}\|\right| \leq\left\|J z_{n, i}-J \tilde{x}\right\| \rightarrow 0 \quad \text { as } n \rightarrow \infty, \forall i \geq 1
$$

it follows from (4.13), (4.14) and the Kadec-Klee property of $E$ that

$$
\lim _{n \rightarrow \infty} z_{n, i}=\tilde{x}, \quad \forall i \geq 1
$$

For all $i \geq 1$, we consider

$$
\begin{aligned}
d\left(S_{i} z_{n, i}, z_{n, i}\right) & \leq d\left(S_{i} z_{n, i}, z_{n+1, i}\right)+\left\|z_{n+1, i}-x_{n+1}\right\|+\left\|x_{n+1}-x_{n}\right\|+\left\|x_{n}-z_{n, i}\right\| \\
& \leq d\left(S_{i}^{n+1} x_{n}, S_{i}^{n+1} x_{n+1}\right)+\left\|z_{n+1, i}-x_{n+1}\right\|+\left\|x_{n+1}-x_{n}\right\|+\left\|x_{n}-z_{n, i}\right\| \\
& \leq L_{i}\left\|x_{n}-x_{n+1}\right\|+\left\|z_{n+1, i}-x_{n+1}\right\|+\left\|x_{n+1}-x_{n}\right\|+\left\|x_{n}-z_{n, i}\right\| \\
& =\left(L_{i}+1\right)\left\|x_{n}-x_{n+1}\right\|+\left\|z_{n+1, i}-x_{n+1}\right\|+\left\|x_{n}-z_{n, i}\right\| .
\end{aligned}
$$

From (4.4) and (4.15), we get that $d\left(S_{i} z_{n, i}, z_{n, i}\right) \rightarrow 0$ as $n \rightarrow \infty$ for all $i \geq 1$. By (4.15) and the closedness of $S_{i}$, we have $\tilde{x} \in S_{i} \tilde{x}$ for all $i \geq 1$, and so $\tilde{x} \in \mathcal{F}$.

Step 5. We show that $\tilde{x} \in M E P(f, \varphi, C)$. Since $u_{n}=T_{r_{n}} w_{n}$, we derive

$$
f\left(u_{n}, y\right)+\varphi(y)+\frac{1}{r_{n}}\left\langle y-u_{n}, J u_{n}-J w_{n}\right\rangle \geq \varphi\left(u_{n}\right), \quad \forall y \in C .
$$

From relaxed $\xi$-monotonicity of $f$, we have

$$
\frac{1}{r_{n}}\left\langle y-u_{n}, J u_{n}-J w_{n}\right\rangle+\varphi(y)-\varphi\left(u_{n}\right) \geq-f\left(u_{n}, y\right) \geq f\left(y, u_{n}\right)-\xi\left(y-u_{n}\right), \quad \forall y \in C .
$$


Since $\frac{J u_{n}-J w_{n}}{r_{n}} \rightarrow 0$ and $u_{n} \rightarrow \tilde{x}$. By (A4), the lower semicontinuity of $\varphi$ and the upper semicontinuity of $\xi$, we have

$$
\begin{aligned}
f(y, \tilde{x})-\xi(y-\tilde{x}) & \leq \liminf _{n \rightarrow \infty} f\left(y, u_{n}\right)-\limsup _{n \rightarrow \infty} \xi\left(y-u_{n}\right) \\
& \leq \liminf _{n \rightarrow \infty}\left\{f\left(y, u_{n}\right)-\xi\left(y-u_{n}\right)\right\} \\
& \leq \liminf _{n \rightarrow \infty}\left\{\frac{1}{r_{n}}\left\langle y-u_{n}, J u_{n}-J w_{n}\right\rangle+\varphi(y)-\varphi\left(u_{n}\right)\right\} \\
& =\varphi(y)-\limsup _{n \rightarrow \infty} \varphi\left(u_{n}\right) \\
& =\varphi(y)-\varphi(\tilde{x}), \quad \forall y \in C .
\end{aligned}
$$

For all $y \in C$ and $t \in(0,1]$, let $y_{t}=t y+(1-t) \tilde{x}$. Since $C$ is convex, we have $y_{t} \in C$, and then

$$
f\left(y_{t}, \tilde{x}\right)-\varphi\left(y_{t}\right)+\varphi(\tilde{x}) \leq \xi\left(y_{t}-\tilde{x}\right) .
$$

Using (A1) and (A4), we have

$$
0=f\left(y_{t}, y_{t}\right) \leq(1-t) f\left(y_{t}, \tilde{x}\right)+t f\left(y_{t}, y\right) .
$$

The convexity of the function $\varphi$ implies that

$$
\varphi\left(y_{t}\right)=\varphi((1-t) \tilde{x}+t y) \leq(1-t) \varphi(\tilde{x})+t \varphi(y) .
$$

This implies that

$$
\begin{aligned}
0 & =f\left(y_{t}, y_{t}\right) \\
& \leq(1-t) f\left(y_{t}, \tilde{x}\right)+t f\left(y_{t}, y\right) \\
& \leq t f\left(y_{t}, y\right)+(1-t)\left[\varphi\left(y_{t}\right)-\varphi(\tilde{x})+\xi\left(y_{t}-\tilde{x}\right)\right] \\
& \leq t f\left(y_{t}, y\right)+(1-t) t\left[\varphi(y)-\varphi(\tilde{x})+t^{p-1} \xi(y-\tilde{x})\right] .
\end{aligned}
$$

This implies that

$$
0 \leq f\left(y_{t}, y\right)+(1-t)\left[\varphi(y)-\varphi(\tilde{x})+t^{p-1} \xi(y-\tilde{x})\right] .
$$

By (A3) and $p>1$, taking the upper limit $t \rightarrow 0$ in (4.18), we get

$$
f(\tilde{x}, y)+\varphi(y)-\varphi(\tilde{x}) \geq 0, \quad \forall y \in C .
$$

Therefore, $\tilde{x} \in M E P(f, \varphi, C)$.

Step 6. Finally, we prove that $\tilde{x}=\Pi_{\Omega} x_{0}$. Let $w=\Pi_{\Omega} x_{0}$. Then $\phi\left(w, x_{0}\right) \leq \phi\left(\tilde{x}, x_{0}\right)$.

Since $w \in \Omega \subset C_{n}$, for all $n \geq 0$ and $x_{n} \in \Pi_{C_{n}} x_{0}$, we have

$$
\phi\left(x_{n}, x_{0}\right) \leq \phi\left(w, x_{0}\right), \quad \forall n \geq 0 .
$$


Since $x_{n} \rightarrow \tilde{x}$, we get that

$$
\begin{aligned}
\phi\left(\tilde{x}, x_{0}\right) & =\|\tilde{x}\|-2\left\langle\tilde{x}, J x_{0}\right\rangle+\left\|x_{0}\right\|^{2} \\
& =\lim _{n \rightarrow \infty}\left\{\left\|x_{n}\right\|-2\left\langle x_{n}, J x_{0}\right\rangle+\left\|x_{0}\right\|^{2}\right\} \\
& =\lim _{n \rightarrow \infty} \phi\left(x_{n}, x_{0}\right) \leq \phi\left(w, x_{0}\right) .
\end{aligned}
$$

Hence $x_{n} \rightarrow \tilde{x}=\Pi_{\Omega} x_{0}$.

In the case of $f \equiv 0$ and $\varphi \equiv 0$ in Theorem 4.3, we have the following corollary.

Corollary 4.4 Let E be a real uniformly smooth and strictly convex Banach space with the Kadec-Klee property, and let $C$ be a nonempty, bounded, closed and convex subset of $E$. Let $\left\{S_{i}: C \rightarrow C B(C)\right\}_{i=1}^{\infty}$ be a family of closed and uniformly quasi- $\phi$-asymptotically nonexpansive multivalued mappings with a sequence $\left\{l_{n}\right\} \subset[1, \infty), l_{n} \rightarrow 1$. Suppose that for each $i \geq 1, S_{i}$ is uniformly $L_{i}$-Lipschitz continuous and $\mathcal{F} \neq \emptyset$. Let $\left\{x_{n}\right\}$ be a sequence in $C$ generated by

$$
\left\{\begin{array}{l}
x_{0} \in C, \quad C_{0}=C \\
w_{n}=J^{-1}\left(\alpha_{n, 0} J x_{0}+\sum_{i=1}^{\infty} \alpha_{n, i} J z_{n, i}\right), \quad z_{n, i} \in S_{i}^{n} x_{n}, \\
C_{n+1}=\left\{v \in C_{n}: \phi\left(v, w_{n}\right) \leq \alpha_{n, 0} \phi\left(v, x_{0}\right)+\left(1-\alpha_{n, 0}\right) \phi\left(v, x_{n}\right)+\zeta_{n}\right\} \\
x_{n+1}=\prod_{C_{n+1}} x_{0}, \quad n \geq 0,
\end{array}\right.
$$

where $\left\{\alpha_{n}\right\} \subset[0,1]$, and $\zeta_{n}=\sup _{u \in F(S)}\left(l_{n}-1\right) \phi\left(u, x_{n}\right)$. If $\lim _{n \rightarrow \infty} \alpha_{n}=0$, then $\left\{x_{n}\right\}$ converges strongly as $n \rightarrow \infty$ to $\Pi_{\Omega} x_{0}$, where $\Omega:=F(S) \cap M E P(f, \varphi, K)$.

If $S_{i}=S$, for all $i \geq 1$, then the following corollary follows from Theorem 4.3.

Corollary 4.5 Let E be a real uniformly smooth and strictly convex Banach space with the Kadec-Klee property, and let $C$ be a nonempty, bounded, closed and convex subset of E. Let $f$ be a bifunction from $C \times C$ to $\mathbb{R}$ satisfying (A1)-(A4), and let $\varphi$ be a lower semicontinuous and convex function from $C$ to $\mathbb{R}$. Let $S: C \rightarrow C B(C)$ be a closed and uniformly L-Lipschitz continuous quasi- $\phi$-asymptotically nonexpansive multivalued mapping with a sequence $\left\{l_{n}\right\} \subset[1, \infty), l_{n} \rightarrow 1$ with $F(S) \cap M E P(f, \varphi, C) \neq \emptyset$. Let $\left\{x_{n}\right\}$ be a sequence in $C$ generated by

$$
\left\{\begin{array}{l}
x_{0} \in C, \quad C_{0}=C \\
w_{n}=J^{-1}\left[\alpha_{n} J x_{0}+\left(1-\alpha_{n}\right) J z_{n}\right], \quad z_{n} \in S^{n} x_{n}, \\
u_{n} \in C \quad \text { such that } \\
f\left(u_{n}, y\right)+\varphi(y)+\frac{1}{r_{n}}\left\langle y-u_{n}, J u_{n}-J w_{n}\right\rangle \geq \varphi\left(u_{n}\right), \quad \forall y \in C, \\
C_{n+1}=\left\{v \in C_{n}: \phi\left(v, u_{n}\right) \leq \alpha_{n, 0} \phi\left(v, x_{0}\right)+\left(1-\alpha_{n, 0}\right) \phi\left(v, x_{n}\right)+\zeta_{n}\right\}, \\
x_{n+1}=\prod_{C_{n+1}} x_{0}, \quad n \geq 0,
\end{array}\right.
$$

where for each $\left\{r_{n}\right\}_{n=0}^{\infty} \subset[a, \infty)$ for some $a>0,\left\{\alpha_{n}\right\} \subset[0,1]$, and $\zeta_{n}=\sup _{u \in F(S)}\left(l_{n}-\right.$ 1) $\phi\left(u, x_{n}\right)$. If $\lim _{n \rightarrow \infty} \alpha_{n}=0$, then $\left\{x_{n}\right\}$ converges strongly as $n \rightarrow \infty$ to $\Pi_{\Omega} x_{0}$, where $\Omega:=F(S) \cap M E P(f, \varphi, K)$. 
In the case of $f \equiv 0$ and $\varphi \equiv 0$ in Corollary 4.4, we can omit the boundedness of $C$ (necessary for the existence of a mapping $T_{r}$ ), so we have the following corollary.

Corollary 4.6 [21, Theorem 3.1] Let E be a real uniformly smooth and strictly convex Banach space with the Kadec-Klee property, let $C$ be a nonempty, closed and convex subset of $E$, and let $S: C \rightarrow C B(C)$ be a closed and uniformly L-Lipschitz continuous quasi- $\phi$ asymptotically nonexpansive multivalued mapping with nonnegative real sequences $\left\{l_{n}\right\} \subset$ $[1, \infty)$ and $l_{n} \rightarrow 1$ with $F(S)$ being a nonempty bounded subset. Let $\left\{\alpha_{n}\right\}$ be a sequence in $(0,1)$. Let $\left\{x_{n}\right\}$ be the sequence generated by

$$
\left\{\begin{array}{l}
x_{0} \in C, \quad C_{0}=C \\
y_{n}=J^{-1}\left[\alpha_{n} J x_{0}+\left(1-\alpha_{n}\right) J z_{n}\right], \quad z_{n} \in S^{n} x_{n}, \\
C_{n+1}=\left\{v \in C_{n}: \phi\left(v, y_{n}\right) \leq \alpha_{n} \phi\left(v, x_{0}\right)+\left(1-\alpha_{n}\right) \phi\left(v, x_{n}\right)+\zeta_{n}\right\} \\
x_{n+1}=\Pi_{C_{n+1}} x_{0}, \quad n \geq 0,
\end{array}\right.
$$

where $\zeta_{n}=\left(l_{n}-1\right) \sup _{p \in F(S)} \phi\left(p, x_{n}\right)$. If $\alpha_{n} \rightarrow 0$, then $\left\{x_{n}\right\}$ converges strongly to $\Pi_{F(S)} x_{0}$.

\section{Application}

We utilize Theorem 4.3 to study a modified Halpern iterative algorithm for a system of mixed equilibrium problems.

Theorem 5.1 Let E be a real uniformly smooth and strictly convex Banach space with the Kadec-Klee property, and let $C$ be a nonempty, bounded, closed and convex subset of E. Let $f_{i}: C \times C \rightarrow \mathbb{R}, i=1,2, \ldots$, be a countable family of bifunctions satisfying conditions (A1)(A4), and let $\varphi_{i}: C \rightarrow \mathbb{R}, i=1,2, \ldots$, be a countable family of lower semicontinuous and convex functions satisfying conditions (i)-(ii) as in Lemma 3.5 with $\Gamma=\bigcap_{i=1}^{\infty} M E P\left(f_{i}, \varphi_{i}, C\right) \neq \emptyset$. Let $\left\{x_{n}\right\}$ be a sequence in $C$ generated by

$$
\left\{\begin{array}{l}
x_{0} \in C, \quad C_{0}=C \\
u_{n, i} \in C \quad \text { such that } \\
f_{i}\left(u_{n, i}, y\right)+\varphi_{i}(y)+\frac{1}{r}\left(y-u_{n, i} J u_{n, i}-J x_{n, i}\right\rangle \geq \varphi\left(u_{n, i}\right), \quad \forall y \in C, r>0, i \geq 1, \\
y_{n}=J^{-1}\left(\alpha_{n, 0} J x_{0}+\sum_{i=1}^{\infty} \alpha_{n, i} J u_{n, i}\right), \\
C_{n+1}=\left\{v \in C_{n}: \phi\left(v, y_{n}\right) \leq \alpha_{n, 0} \phi\left(v, x_{0}\right)+\left(1-\alpha_{n, 0}\right) \phi\left(v, x_{n}\right)+\zeta_{n}\right\}, \\
x_{n+1}=\prod_{C_{n+1}} x_{0}, \quad n \geq 0,
\end{array}\right.
$$

where $\left\{\alpha_{n}\right\} \subset[0,1]$, and $\zeta_{n}=\sup _{u \in F(S)}\left(l_{n}-1\right) \phi\left(u, x_{n}\right)$. If $\lim _{n \rightarrow \infty} \alpha_{n}=0$, then $\left\{x_{n}\right\}$ converges strongly as $n \rightarrow \infty$ to $\Pi_{\Gamma} x_{0}$, which is a common solution of the system of mixed equilibrium problems.

Proof For any $i=1,2, \ldots$, we define a mapping $T_{r, i}(z): E \rightarrow C$ as follows:

$$
T_{r, i}(z)=\left\{x \in C: f_{i}(x, y)+\varphi_{i}(y)+\frac{1}{r}\langle y-x, J x-J z\rangle \geq \varphi_{i}(x), \forall y \in C\right\} .
$$

From Lemma 3.5, we get that $u_{n, i}=T_{r, i} x_{n}$ and $F\left(T_{r, i}\right)=\operatorname{MEP}\left(f_{i}, \varphi_{i}, C\right)$ for all $i=1,2, \ldots$, and $T_{r, i}$ is a countable family of closed quasi- $\phi$-nonexpansive mappings. Thus, (5.1) can 
be written as follows:

$$
\left\{\begin{array}{l}
x_{0} \in C, \quad C_{0}=C \\
y_{n}=J^{-1}\left(\alpha_{n, 0} J x_{0}+\sum_{i=1}^{\infty} \alpha_{n, i} J T_{r, i} x_{n}\right), \\
C_{n+1}=\left\{v \in C_{n}: \phi\left(v, y_{n}\right) \leq \alpha_{n, 0} \phi\left(v, x_{0}\right)+\left(1-\alpha_{n, 0}\right) \phi\left(v, x_{n}\right)+\zeta_{n}\right\} \\
x_{n+1}=\Pi_{C_{n+1}} x_{0}, \quad n \geq 0 .
\end{array}\right.
$$

Therefore, the result can be obtained from Corollary 4.4.

\section{Conclusion}

In this paper, we establish the existence of a solution of the mixed equilibrium problem $\operatorname{MEP}(f, \varphi, C)$ by using the KKM mapping in a Banach space setting, when $f$ is relaxed $\xi$-monotone. Then, by virtue of this result, we introduce a hybrid iterative scheme and prove that our proposed iterative scheme converges strongly to a common element of the set of solutions of $\operatorname{MEP}(f, \varphi, C)$ and the set of common fixed points of a countable family of quasi- $\phi$-asymptotically nonexpansive multivalued mappings.

\section{Competing interests}

The authors declare that they have no competing interests.

\section{Authors' contributions}

Both authors read and approved the final manuscript.

\section{Acknowledgements}

The first author is supported by Naresuan University.

Received: 2 July 2013 Accepted: 2 October 2013 Published: 07 Nov 2013

\section{References}

1. Ceng, L-C, Yao, J-C: A hybrid iterative scheme for mixed equilibrium problems and fixed point problems. J. Comput. Appl. Math. 214, 186-201 (2008)

2. Cholamjiak, P, Suantai, S: Existence and iteration for a mixed equilibrium problem and a countable family of nonexpansive mappings in Banach spaces. Comput. Math. Appl. 61, 2725-2733 (2011)

3. Fang, YP, Huang, NJ: Variational-like inequalities with generalized monotone mappings in Banach spaces. J. Optim. Theory Appl. 118(2), 327-338 (2003)

4. Blum, E, Oettli, W: From optimization and variational inequalities to equilibrium problems. Math. Stud. 63(1-4), 123-145 (1994)

5. Chadli, O, Schaible, S, Yao, JC: Regularized equilibrium problems with an application to noncoercive hemivariational inequalities. J. Optim. Theory Appl. 121, 571-596 (2004)

6. Chadli, O, Wong, NC, Yao, JC: Equilibrium problems with applications to eigenvalue problems. J. Optim. Theory Appl. 117(2), 245-266 (2003)

7. Reich, S: Weak convergence theorems for nonexpansive mappings in Banach spaces. J. Math. Anal. Appl. 67, 274-276 (1979)

8. Matsushita, S, Takahashi, W: Weak and strong convergence theorems for relatively nonexpansive mappings in Banach spaces. Fixed Point Theory Appl. 2004, 37-47 (2004)

9. Matsushita, S, Takahashi, W: A strong convergence theorem for relatively nonexpansive mappings in a Banach space. J. Approx. Theory 134, 257-266 (2005)

10. Takahashi, W, Zembayashi, K: Strong convergence theorem by a new hybrid method for equilibrium problems and relatively nonexpansive mappings. Fixed Point Theory Appl. 2008, Article ID 528476 (2008)

11. Aleyner, A, Reich, S: Block-iterative algorithms for solving convex feasibility problems in Hilbert and in Banach spaces. J. Math. Anal. Appl. 343(1), 427-435 (2008)

12. Plubtieng, S, Ungchittrakool, K: Hybrid iterative methods for convex feasibility problems and fixed point problems of relatively nonexpansive mappings in Banach spaces. Fixed Point Theory Appl. 2008, Article ID 583082 (2008)

13. Plubtieng, S, Ungchittrakool, K: Strong convergence theorems of block iterative methods for a finite family of relatively nonexpansive mappings in Banach spaces. J. Nonlinear Convex Anal. 8(3), 431-450 (2007)

14. Zegeye, $\mathrm{H}$, Shahzad, $\mathrm{N}$ : Convergence theorems for a common point of solutions of equilibrium and fixed point of relatively nonexpansive multivalued mapping problems. Abstr. Appl. Anal. 2012, Article ID 859598 (2012) doi:10.1155/2012/859598

15. Chang, SS, Kim, JK, Wang, XR: Modified block iterative algorithm for solving convex feasibility problems in Banach spaces. J. Inequal. Appl. 2010, Article ID 869684 (2010)

16. Combettes, PL, Hirstoaga, SA: Equilibrium programming in Hilbert spaces. J. Nonlinear Convex Anal. 6(1), 117-136 (2005) 
17. Takahashi, W, Zembayashi, K: Strong and weak convergence theorems for equilibrium problems and relatively nonexpansive mappings in Banach spaces. Nonlinear Anal. 70, 45-57 (2009)

18. Tada, A, Takahashi, W: Strong convergence theorem for an equilibrium problem and a nonexpansive mapping. In: Takahashi, W, Tanaka, T (eds.) Nonlinear Analysis and Convex Analysis, pp. 609-617. Yokohama Publishers, Yokohama (2007)

19. Tada, A, Takahashi, W: Weak and strong convergence theorems for a nonexpansive mapping and an equilibrium problem. J. Optim. Theory Appl. 133(3), 359-370 (2007)

20. Homaeipour, S, Razani, A: Weak and strong convergence theorems for relatively nonexpansive multi-valued mappings in Banach spaces. Fixed Point Theory Appl. 2011, 73 (2011)

21. Yi, L: Strong convergence theorems for modifying Halpern iterations for quasi- $\phi$-asymptotically nonexpansive multivalued mapping in Banach spaces with applications. J. Appl. Math. 2012, Article ID 912545 (2012). doi:10.1155/2012/912545

22. Tan, JF, Chang, SS: Strong convergence theorems for a generalized mixed equilibrium problem and a family of total quasi- $\phi$-asymptotically nonexpansive multivalued mappings in Banach spaces. Abstr. Appl. Anal. 2012, Article ID 147915 (2012). doi:10.1155/2012/147915

23. Cioranescu, I: Geometry of Banach Spaces, Duality Mappings and Nonlinear Problems. Mathematics and Its Applications, vol. 62. Kluwer Academic, Dordrecht (1990)

24. Alber, YI: Metric and generalized projection operators in Banach spaces: properties and applications. In: Kartsatos, AG (ed.) Theory and Applications of Nonlinear Operators of Accretive and Monotone Type, pp. 15-50. Dekker, New York (1996)

25. Fan, K: A generalization of Tychonoffs fixed point theorem. Math. Ann. 142, 305-310 (1961)

10.1186/1687-1812-2013-251

Cite this article as: Wangkeeree and Preechasilp: Iterative approximation methods for mixed equilibrium problems for a countable family of quasi- $\phi$-asymptotically nonexpansive multivalued mappings in Banach spaces. Fixed Point Theory and Applications 2013, 2013:251

\section{Submit your manuscript to a SpringerOpen ${ }^{\circ}$ journal and benefit from:}

- Convenient online submission

- Rigorous peer review

- Immediate publication on acceptance

Open access: articles freely available online

- High visibility within the field

- Retaining the copyright to your article 